\title{
Fuzzy Controlled Single-Stage Converter Fed PV System
}

\author{
R. Durga Bhavani, Gundala Srinivasa Rao
}

\begin{abstract}
This paper shows a new technique for controlling the $L G, L L$ and $L L L$ faults by the fuzzy-integral decision fusion technique is designed to the grid connected to PV system. The method firstly constructs a criterion set which considers for LG, LLL, LL faults. The control targets, for example, mppt, synchronization of grid and regular limit in yield current, are considered in single-stage converter for excessive productivity and straightforward energy converter by using the fluffy controller. On this premise, it is indicated by using fault qualities, paradigm in the set is for a part used to do LG, LL and LLL faults analysis, and fault measure is produced from every model. The real and reactive power is restricted by using utilizing $d q$ segments of grid current. The new controller shows the sturdy exhibition and full of life steadiness of the DG unit device as for the channel parameters vulnerabilities, grid impedance, grid frequency, and grid voltage simply as the vague burden elements that comprise unequal burdens and nonlinear burdens with regular and between symphonious currents. It must remark that the local remuneration of the heaps with between symphonious present days utilizing a DG unit device is first projected in this paper. At that factor when contrasted and the mainstream parallel corresponding thunderous manipulate system, proposed controller affords smoother transient responses and a lower dimension of present day twisting. The presentation of the projected manipulate approach is demonstrated in MATLAB/SimPower Systems toolbox.
\end{abstract}

Keywords: Fuzzy-integral decision fusion technique, DG unit, LG LL LLL faults, fuzzy controller

\section{INTRODUCTION}

In the last few years, the energy extracted from the photovoltaic (PV) systems and connecting to utility grid has increased due to advancement in technology and availability of power electronic devices and the governments came up with incentive programs [2]. In the grid-connected PV systems, the most necessary conditions are to focus on cost effectiveness and improvement of efficiency, reliability of both the PV panels, converters [3], [4]. To attain these, three-phase single-stage dc-to-ac energy converter device reflect on consideration on being the nice desire for high power utility system Photovoltaic device [5]. The rapid increase in the expansion of coupling of this megawatt solar structures in the distribution community requires learn about of PV system affects on the distribution network and attainment of controllers beneath steady-state and dynamic conditions. The dynamic response of power electronic device is analyzed by means of its structure; manage techniques, distribution network parameters, and climate conditions.

Revised Version Manuscript Received on August 19, 2019.

R. Durga Bhavani, PG Scholar, Department of EEE, CMR College of Engineering \& Technology, Kandlakoya, Hyderabad, Telangana, India. (email: bhavanirasuri95@gmail.com)

Dr.Gundala Srinivasa Rao, Assistant Professor, Department of EEE, CMR College of Engineering \& Technology, Kandlakoya, Hyderabad, Telangana, India.(email: drgundalasrinivasarao@cmrcet.org)
Much literature have mentioned on these elements initially. References [6]-[8] counseled exceptional power digital converter topologies for distributed generation. A survey of greatest wide variety strength factor monitoring (MPPT), the frequent factor of Photovoltaic system, is mentioned in [9] -[11].Most of the work has been considered on two-stage Photovoltaic system. A few references have taken to manage components powers and balance for single-stage high-power Photovoltaic. References [11]-[14] inspect manage strategies for single-stage of PV device except balance consideration. Reference [11] depicts the energy a problem however does now is not considered about grid connection and reactive strength control. In [12], PV system like reactive power ancillary provider is proposed.

An incremental conductance MPPT method for active power control, a FBL technique for dc-link voltage control and d-axis control are used, and also a q-axis current controller is preferred for control of reactive power.

- FBL scheme is implemented in dc-link voltage controller design, to reduce the impact of distribution system parameters variations and the nonlinearities occurred for characteristics PV systems.

- Not as same as the regular scheme mentioned in [14], FBL technique is implemented in design of voltage controller to accelerate the results by making controller easier.

- An additional block called compensation for grid voltage dip is used to reduce the destabilization of controllers.

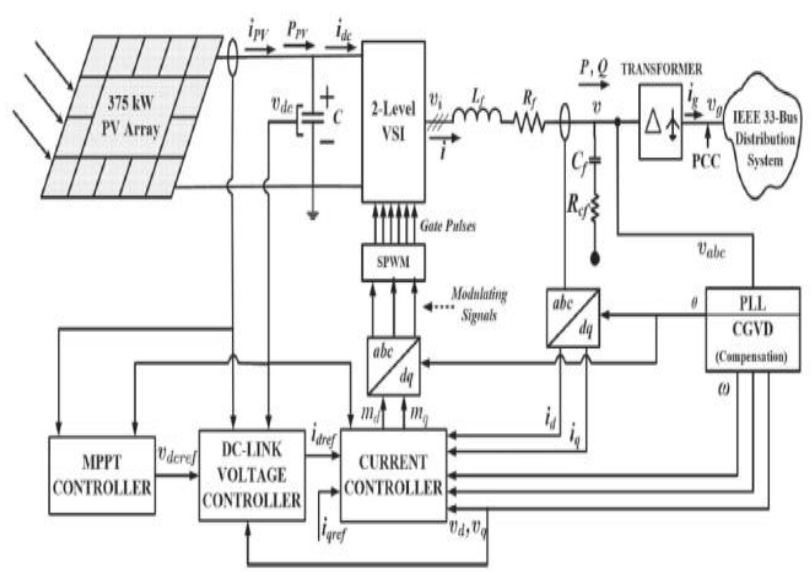

Fig. 1. Single unit of 375-kW Subsystem. 


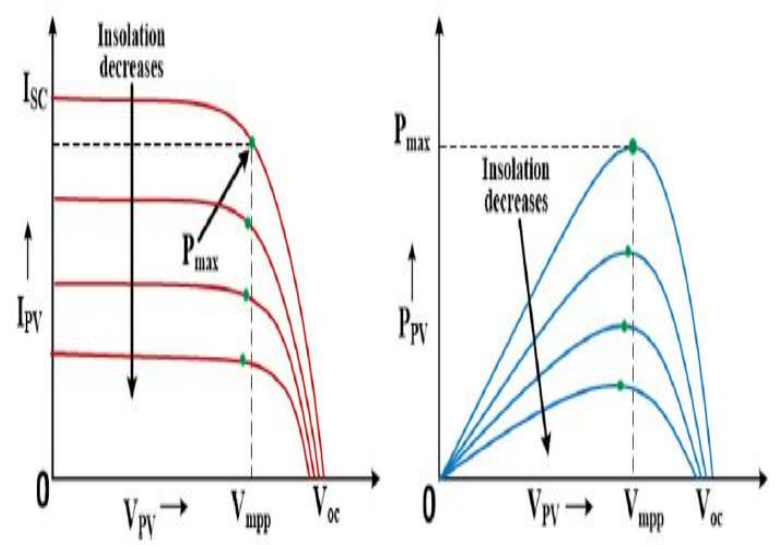

Fig.2. MPPT Photovoltaic panel properties

To make up for the nearby burden symphonious current, numerous sorts of constant extraction approaches have be proposed [10], including quick power (pq) hypothesis [11], second-request summed up integrator (SOGI) [12], the postponed sign abrogation based identification [13], and Fourier transformation based discovery [14].

In addition, under different states of various introductory fault voltage edge and distinctive fault obstruction, electric parameter trademark brought about by LG, LL, LLL is assorted and complex. The customary LG, LL, LLL fault analysis techniques are generally founded on fractional fault trademark, (for example, transient fault signal adequacy, transient fault signal stage, relentless state fault signal sufficiency, consistent state fault signal stage, etc) and as indicated by single measure, (for example, transient wavelet plentifulness examination paradigm, transient wavelet connection rule, unfaltering state abundance correlation rule, enduring state relative stage basis, etc). Be that as it may, each rule has its very own application degree, and it's difficult to utilize a solitary foundation to realize viable fault finding under different LG, LL and LLL fault conditions. In perspective on this, to improve unwavering quality and versatility of SLG fault analysis, a conclusion strategy dependent on fluffy basic choice combination system is proposed in this paper. In this paper there is an examination between the PI controller and the fluffy for the LG, LL and LLL fault determination. Thereafter, the fault measure is fluffy coordinated about fluffy measure in the standard set to realize successful combination of different analysis results and acquire increasingly dependable end for LG, LL and LLL fault determination. Reproduction demonstrates that, under different states of fluffy controller at neutral-point establishing modes diverse introductory fault voltage edge and distinctive fault opposition, this strategy could generally find fault line precisely.

\section{PV SYSTEM ARCHITECTURE}

Fig. 1 demonstrates three-phase inverter fed Photovoltaic framework related to IEEE 33-transport circulation lattice. The system consists of numerous fundamental components, for example, Photovoltaic cluster; a three-phase three-level balanced voltage source inverter (VSI) with an replacing recurrence of six kHz; a low-pass channel; and the transformer associated with the distribution matrix at a point of common coupling (PCC). The attributes of an ordinary Photovoltaic cluster are demonstrated as follows, it is appeared, as voltage zero, control yield is zero. The electricity increments with the voltage up to a unique most extreme electricity factor (MPP). At that point, electricity and cutting-edge each reduction until the open-circuit voltage goes to zero.

The PV showcase is related with the dc side of the VSI with a dc-connect capacitor. The control of this VSI depends on sinusoidal width balance. The output side of the inverters is related with the constant channels. The association section of the channel comprises of an inductor, and the shunt department is having delta related capacitors in association with obstruction. By consolidating a few portions of such PV frameworks in parallel, bigger restriction PV frameworks can be shaped, as seemed a three stage single-organize 1.5-MW PV framework is acknowledged by using $4375-\mathrm{kW}$ frameworks.

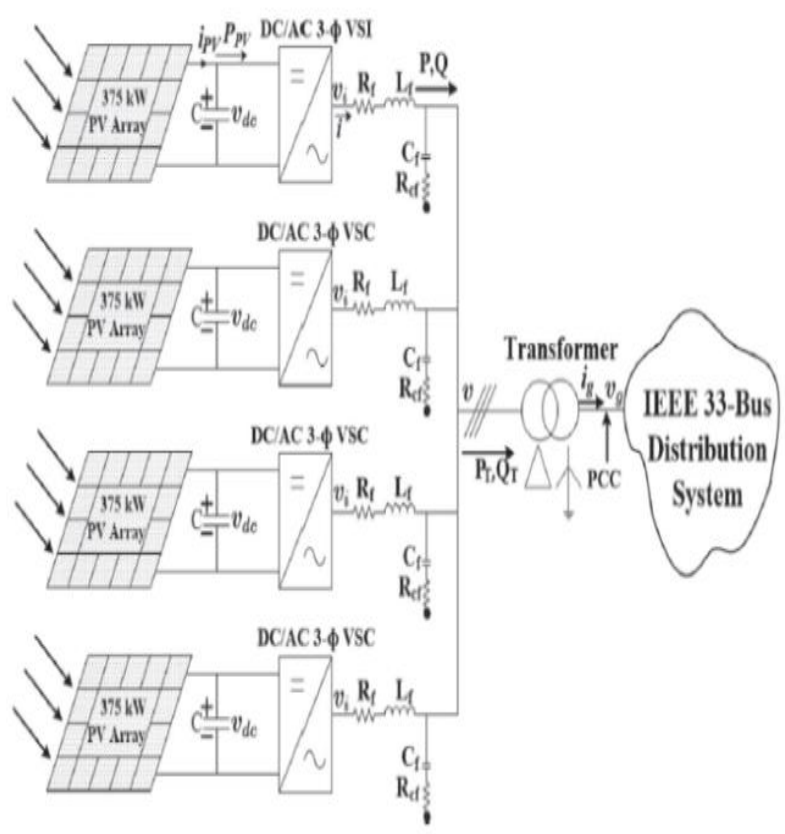

Fig. 3. Total 1.5-MW framework.

\section{CONTROL SCHEMES}

\section{A. Photovoltaic Circuit}

The circuit contains a dc-link capacitor, a collection filter, the shunt department of the filter, and impedance of transformer. The elements in the dc-interface capacitor is established as follows; the variable Vdc. The numerical mannequin of the elements of inverter in the arrangement channel is characterized via the accompanying prerequisites in dq outline: 


$$
\begin{aligned}
& L \frac{d i_{d}}{d t}=-R_{f} \dot{l}_{d}+\omega L L_{i}+v_{d}=v_{d} \\
& L f \frac{d i_{q}}{d t}=-B f l_{q}=\omega L_{f} l_{d}+v_{i q}-v_{q}
\end{aligned}
$$

the factors of shunt section and the impedance of transformer are given by

$$
\begin{aligned}
& C_{f} \frac{d v}{d t}=i-N i_{g}+C_{f} R_{c f}\left(\frac{d i}{d t}-\frac{d i_{g}}{d t}\right) \\
& L_{T} \frac{d i_{g}}{d t}=-R_{T} i_{g}+N v-v_{g}
\end{aligned}
$$

Where N, LT, and RT are the flip proportion, the inductance, and the obstruction of the transformer, separately. ig and vg of community infused current and voltage, individually. State elements id, (1) iq, (2) vd, vq, igd (3) and igq are characterized under (4).

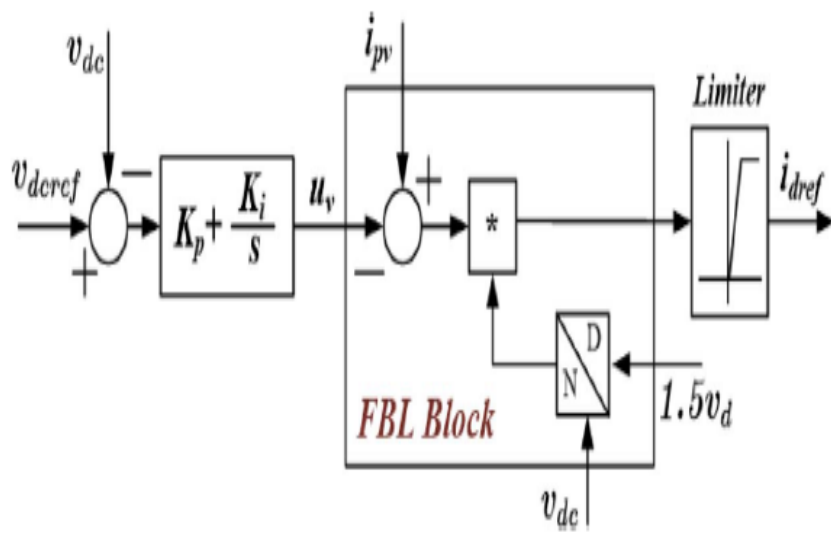

Fig. 4. DC-Interface voltage controller diagram.

\section{B. Grid Synchronization}

To synchronize the photovoltaic system with grid, the amplitude and $\theta$ of the grid voltage are considered. A commonly used approach based on conventional segment locked loop (PLL) [20] with a modified block is considered. This block is considered to be a compensator for grid voltage disturbance (CGVD). The d- and q-axes aspects vd and vq of the grid voltage vabc are handed via a compensator block and used in the PLL scheme. By placing the q-axis voltage element equal to zero, the PLL $\theta$ is made equal to the segment perspective of the grid section voltage VA, as proven below. By PWM oscillations in the $\mathrm{d}$ - and q-axes voltage which, therefore it results in better working of remaining controllers.

\section{DC-Interface Voltage Control}

The dc-interface voltage controller displayed relies upon on FBL machine [22]. The controller is utilized to direct the dc-interface capacitor voltage as indicated via the reference voltage vdcref, which is chosen by using the MPPT plot. The dc-connect voltage guiding principle is completed via manage of direct pivot current, which, thus, controls the proper power infusion into the matrix. Beneath verified figure is the dc-connect voltage manipulate conspire, which is planned based totally on the FBL strategy. Disregarding the inverter control misfortune, as indicated by using the impact equalization of the two terminals of the inverter in unfaltering state, PPV ought to be equivalent to the have an effect on yield of the VSI output side terminals, which equals to yield matrix influence $\mathrm{P}$, overlooking the channel have an impact on misfortune. The controller chips away at the voltage factors of dc-connect capacitor established on electricity balance rule, as indicated by

$$
\frac{d}{d t}\left(\frac{1}{2} C v_{\mathrm{dc}}^{2}\right)=P_{\mathrm{PV}}-P .
$$

By the use of eqn (5) it can be simplified by using beneath eqn

$$
C \frac{d v_{\mathrm{dc}}}{d t}=i_{\mathrm{PV}}-\frac{3}{2} \frac{v_{d}}{v_{\mathrm{dc}}} i_{d}
$$

Where vd and id are the dq-hub framework voltage and current, individually; and $\mathrm{P}$ is equal to three by two times of Vd*Id [23].

By the FBL approach [24] as indicated, let $\mathrm{f}(\mathrm{x})$ and $\mathrm{b}(\mathrm{x})$ are nonlinear factors of a framework with states $\mathrm{x}$, as

$$
\dot{x}=f(x)+b(x) * u_{i}
$$

Use the manage input ui as

$$
u_{i}=\frac{1}{b}\left[u_{v}-f\right]
$$

Cancelling out the non linearities as

$$
\dot{x}=u_{v} \text {. }
$$

Considering id $(=(2 / 3)(\mathrm{vdc} / \mathrm{vd})[\mathrm{iPV}-\mathrm{uv}])$ as a linear differential equation of control input is written as shown below.

$$
C \frac{d}{d t}\left(v_{\mathrm{dc}}\right)=u_{v}
$$

From (9), Transfer function of a plant is derived as below

$$
G_{p}(s)=\frac{v_{\mathrm{dc}}(s)}{u_{v}(s)}=\frac{1}{s C} .
$$

For the principal plant move work, a PI controller Gvdc c is organized with genuine stage edge and settling time. 


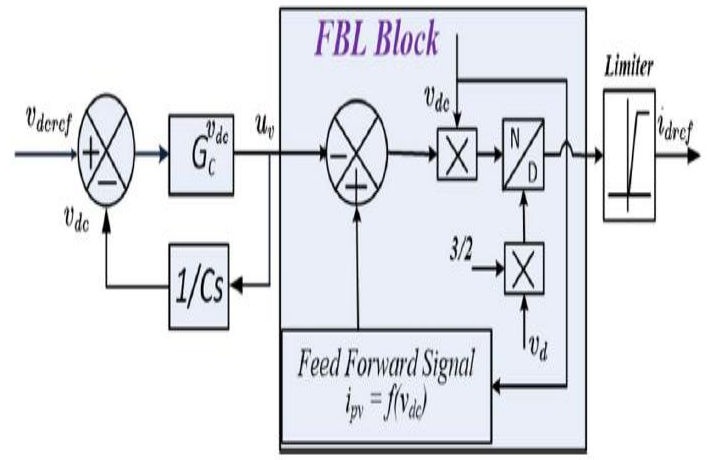

Fig. 5. Dc-Interface voltage control block diagram.

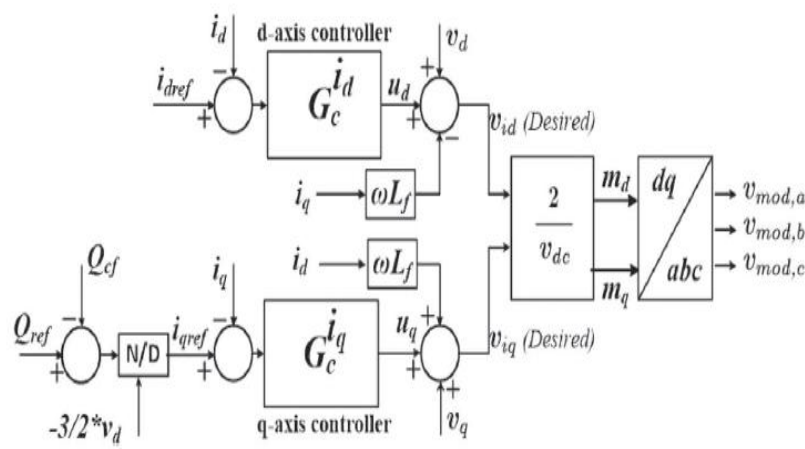

Fig. 6. Real and reactive energy manage scheme.

\section{Current Controller}

To create the adjusting signals for VSI, the proposed dq hub current manage methodology is discussed in Dc-link controller. From the existing controller, the yield voltage signals (vid and viq) for the inverter are acquired. In exhibiting of the present controller, the inverter is viewed as a harmony increase square, and postponement of time delivered about by the inverter to create the yield voltage signal is ignored. The prerequisites portraying the elements of the d-and q-tomahawks modern controllers in time house are inferred as

$$
\begin{aligned}
\frac{d v_{i d}}{d t}= & K_{P}\left(\frac{d i_{\mathrm{dref}}}{d t}-\frac{d i_{d}}{d t}\right)+K_{I}\left(i_{\mathrm{dref}}-i_{d}\right)+\frac{d v_{d}}{d t} \\
& -\omega L \frac{d i_{q}}{d t}-L i_{q} \frac{d \omega}{d t} \\
\frac{d v_{i q}}{d t}= & -K_{P} \frac{d i_{q}}{d t}-K_{I} i_{q}+\frac{d v_{q}}{d t}+\omega L \frac{d i_{d}}{d t}+L i_{d} \frac{d \omega}{d t}
\end{aligned}
$$

Where vid and viq are the kingdom factors. Kp and Ki are the corresponding fundamental additions of the PI controllers (Gid c \& Giq c).

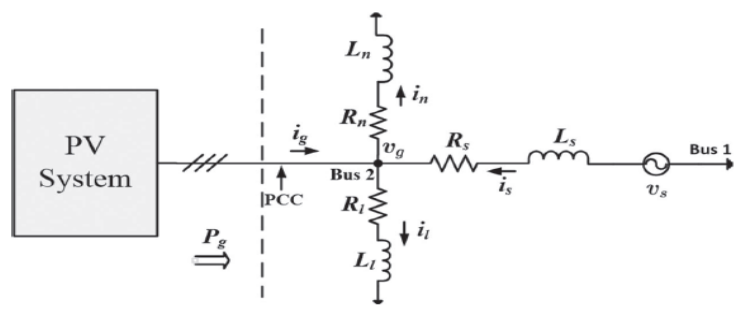

Fig. 7. PV framework combination with identical distribution network.

\section{FUZZY-INTEGRAL DECISION FUSION TECHNIQUE}

Fluffy necessary is a sort of nonlinear choice combination technique dependent on fluffy thickness. It could deal with the cooperation between elements which are autonomous. The fundamental procedure does not just incorporate the nearby yield of each factor, yet in addition considers the significance level of each factor. So as to improve the versatility and unwavering quality of symptomatic strategy, fluffy essential choice combination technique could be connected. In light of DN genuine working condition, it considers the versatile distinction of each customary shortcoming symptomatic technique, utilizes numerous SLG-flaw qualities, incorporates different nearby demonstrative outcomes, and makes a conclusive inference. Contrasted and other choice combination strategy, fluffy indispensable keeps away from the earlier data discourse, and does not have to make the suspicion of freedom among neighborhood symptomatic strategies. In the interim, it could more readily manage the vulnerability brought about by observational incentive during determination process. Therefore, fluffy essential is progressively appropriate for DN issue analysis.

The reason of choice combination is , for every nearby indicative technique $m_{i}(i=1,2, \ldots, n)$ getting the information (deficiency trademark the output (fault measure $h_{i j}(i=1,2, \ldots, n j=1,2, \ldots, m)$ of each suspected fault object $(i=1,2, \ldots, n j=1,2, \ldots, m)$ and fuzzy density gi.

In light of this interest, for SLG shortcoming analysis in circulation organize, right off the bat, this paper utilizes wavelet technique for sign's peculiarity location and highlight extraction to get the exact data about event time, transient recurrence attributes, relentless state qualities of deficiency sign and unequal working qualities of DN's own.

At that point, utilizing the transient recurrence qualities and consistent state attributes of unadulterated issue signal which avoids DN's own lopsided working variable, for every neighborhood symptomatic technique $m_{i}(i=1,2, \ldots, n)$ this paper proposes a strategy to produce shortcoming measure hij of each speculated deficiency object. $p_{j}(j=1,2, \ldots, m)$.

Also, through the correlation between DN's real status to blame minute and relevant state of every neighborhood symptomatic technique, this paper builds up the quantitative measure strategy for certainty for every nearby demonstrative strategy ( $1,2, \ldots$, ) I $\mathrm{m} \mathrm{I} \square \mathrm{n}$, and changes over the certainty into fluffy thickness I $g$ for fluffy fundamental.

In light of the above work, as indicated by fluffy fundamental choice combination strategy, this paper utilizes fluffy thickness circulation in the arrangement of neighborhood shortcoming demonstrative techniques $M\left(M=\left\{m_{i}(i=1,2, \ldots, n)\right\}\right)$ to get fluffy measure $\mathrm{g}($.$) of monotonic$ subsets in $\mathrm{M}$, and afterward doe fluffy coordination of deficiency measure $\mathrm{ij} \mathrm{h}$ about fluffy measure $\mathrm{g}($.) in $\mathrm{M}$ to get a solitary outcome, which means incorporating numerous symptomatic outcomes and drawing an authoritative and solid finding end. 


\section{DISCUSSION \& RESULTS}

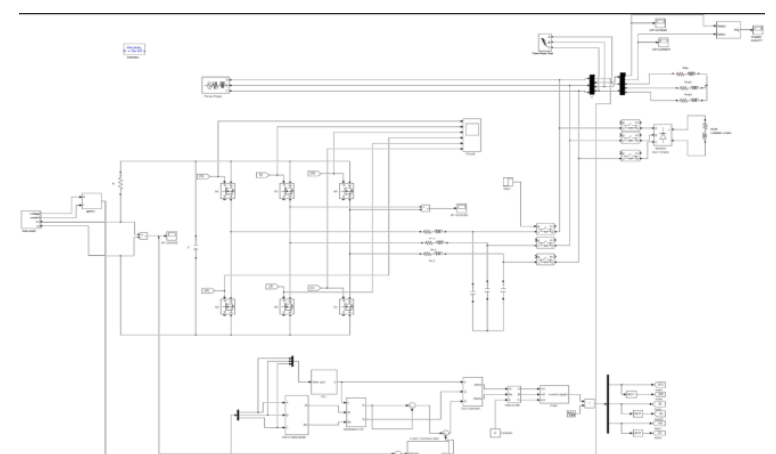

Fig.10.Simulink circuit of Fuzzy controlled single-stage converter fed Pv system

A. Performance of the DC-Interface Voltage Controller

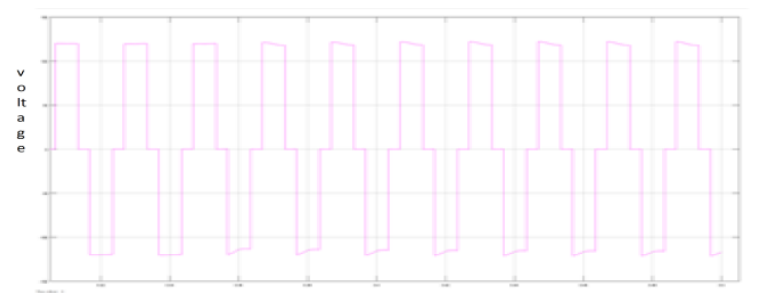

Fig.11. Source voltages

Here in the fig 11 the out wave form of three phase multi-inverter had been shown.

B. MPPT and Current Controller Performance

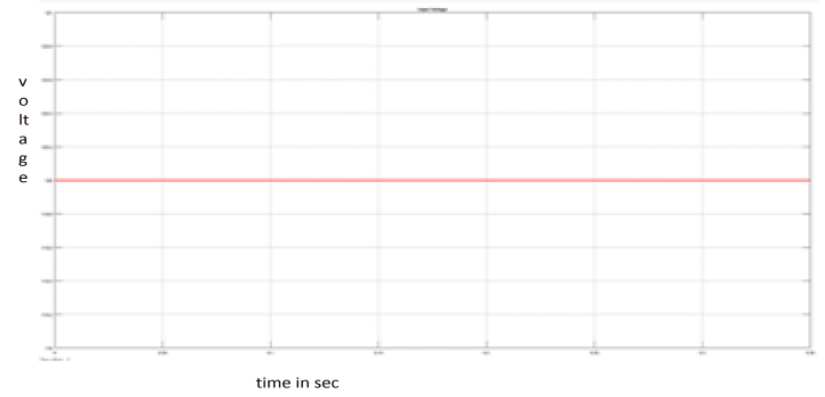

Fig.12. PV panel output after the performance of the MPPT technique.

The MPPT technique is replaced by fuzzy controller for the fast response.

C. Voltage Dip Response

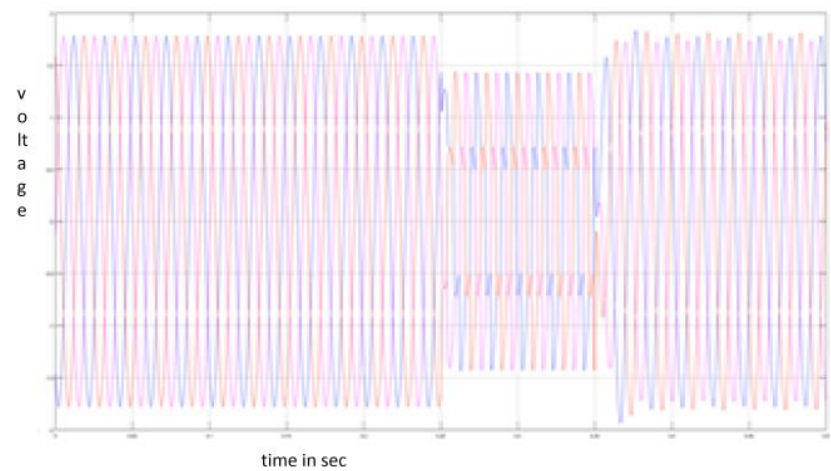

(a)

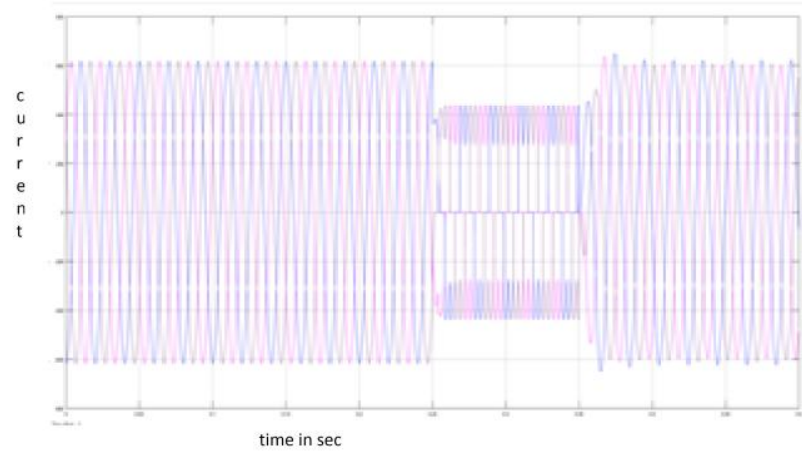

(b)

Fig .13.Dips at the loads. (a) voltages (b) currents

In the above fig 13. The voltage dips and current dips are occurred when the nonlinear load is varied in the power system.

D.Three-Phase Fault

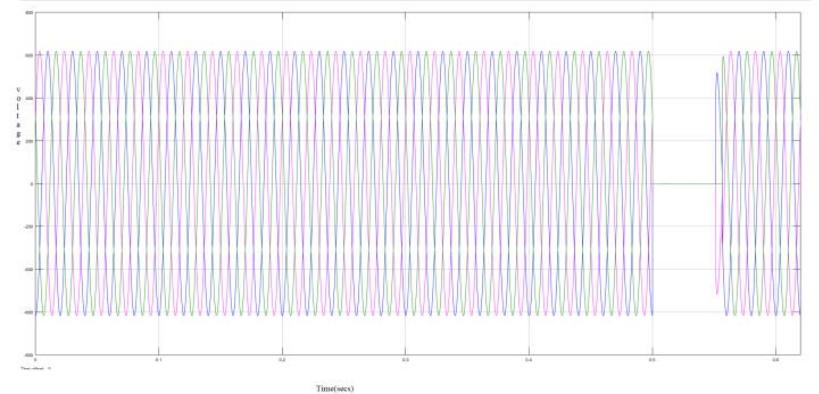

(a)

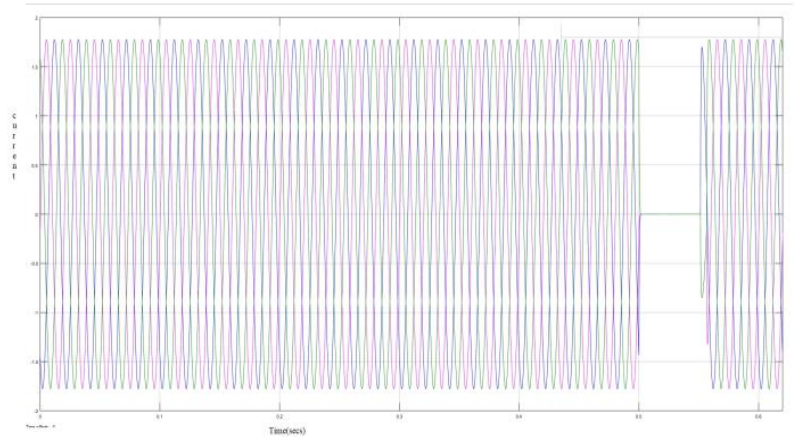

(b)

Fig.14. Three-Phase fault (a) voltages (b) currents Fig.14. Shows the Three-Phase faults occurred in the power system.

\section{E. LG Fault}




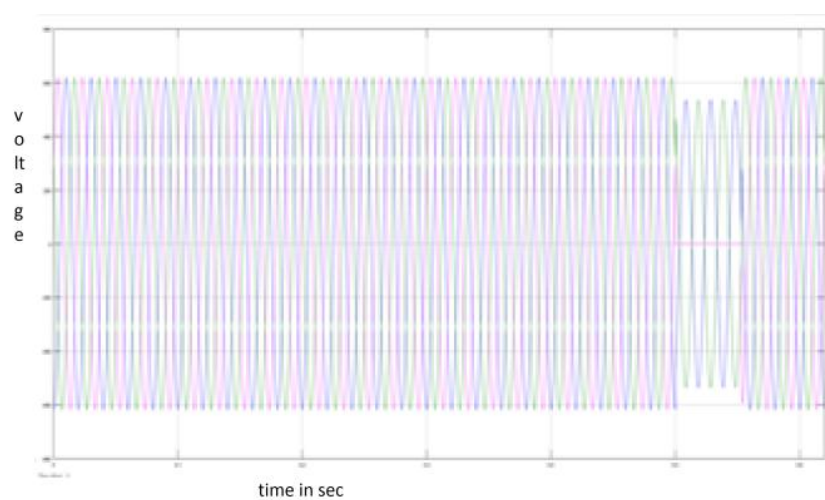

(a)

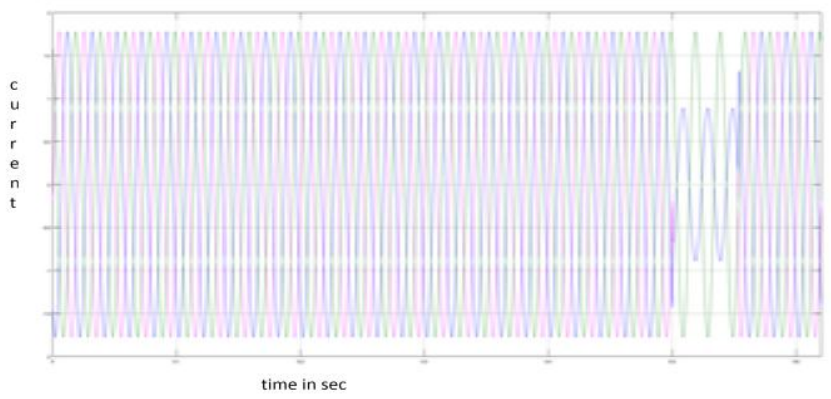

(b)

Fig.15. LG fault analysis (a) voltages (b) currents. Here in the fig. 15. The line to ground fault is occurred.

\section{F.THD:}

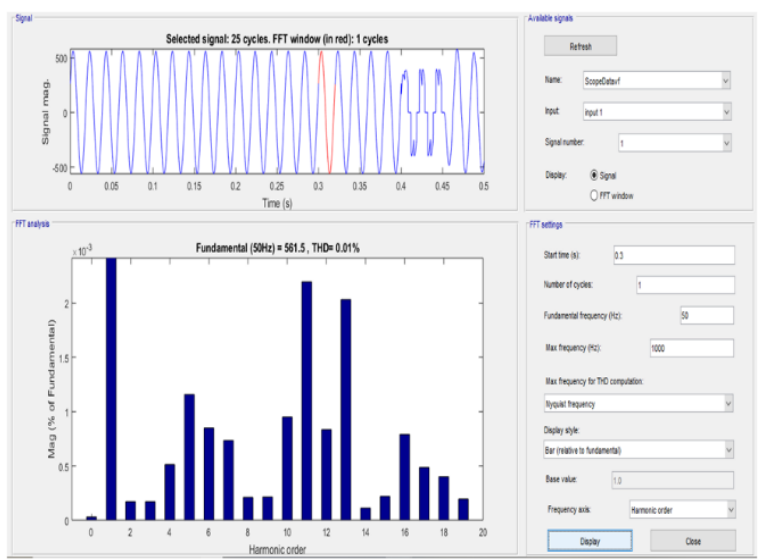

Fig.16. THD of PI CONTROLLER

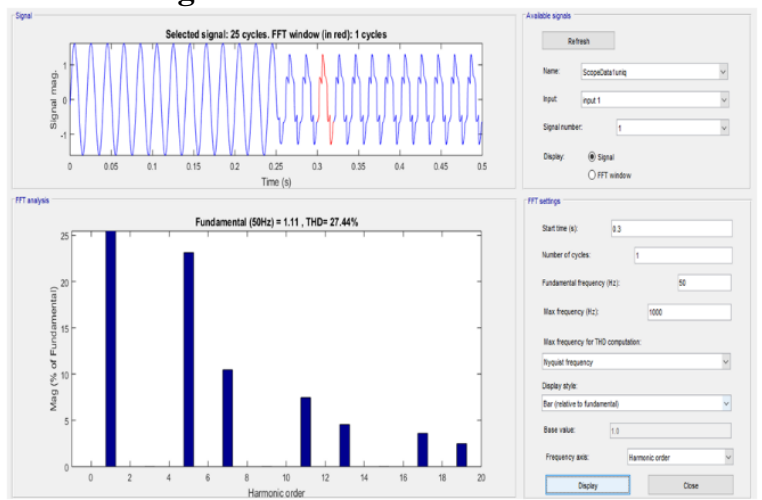

Fig.17. THD of FUZZY CONTROLLER

By comparing the THDs of PI and Fuzzy are shown. There the better performance is given by the FUZZY controller. With the lowest value of 0.01 percentage.

\section{CONCLUSION}

In this undertaking, fuzzy indispensable choice combination technique is connected for issue examination. In view of different qualities of LG, LL and LLL shortcoming extricated by wavelet, this technique completely considers the dependability and versatility distinction of every nearby investigation measure incorporates numerous neighborhood examination results and gives an authoritative investigation end, which lessens the vulnerability impact brought about by experimental qualities and exceptionally builds the determination unwavering quality and flexibility. At the voltage dip of the grid, the dynamic response is greatly reduced, results in less oscillations and contortion in waveforms. Simulation results uncover demonstrates that, regardless of whether the nearby investigation outputs are reliable or not, with considered technique would generally find fault on the line precisely in different states in various PI controller establishing strategies, diverse starting fault voltage edge just as various change obstruction.

\section{REFERENCES}

1. Vivek Nandan Lal and S. N. Singh, "Control and Performance Analysis of a Single-Stage Utility-Scale Grid-Connected PV System" IEEE systems journal, vol. 11, no. 3, september 2017.

2. M. Oprisan and S. Pneumaticos, "Potential for electricity generation from emerging renewable sources in Canada," in Proc. IEEE EIC Climate Change Technol. Conf., May 2006, pp. 1-10.

3. G. Petrone, G. Spagnuolo, R. Teodorescu, M. Veerachary, and M. Vitelli, "Reliability issues in photovoltaic power processing systems," IEEE Trans. Ind. Electron., vol. 55, no. 7, pp. 2569-2580, Jul. 2008.

4. S. Jain and V. Agarwal, "A single-stage grid connected inverter topology for solar PV systems with maximum power point tracking," IEEE Trans. Power Electron., vol. 22, no. 5, pp. 1928-1940, Jul. 2007.

5. F. Katiraei and J. Aguero, "Solar PV integration challenges," IEEE Power Energy Mag., vol. 9, no. 3, pp. 62-71, May-Jun. 2011.

6. S. H. Ko, S. Lee, H. Dehbonei, and C. Nayar, "Application of voltageand current-controlled voltage source inverters for distributed generation systems," IEEE Trans. Energy Convers., vol. 21, no. 3, pp. 782-792, Sep. 2006.

7. F. Blaabjerg, Z. Chen, and S. Kjaer, "Power electronics as efficient interface in dispersed power generation systems," IEEE Trans. Power Electron., vol. 19, no. 5, pp. 1184-1194, Sep. 2004.

8. J. Carrasco et al., "Power-electronic systems for the grid integration of renewable energy sources: A survey," IEEE Trans. Ind. Electron., vol. 53, no. 4, pp. 1002-1016, Jun. 2006.

9. T. Esram and P. Chapman, "Comparison of photovoltaic array maximum power point tracking techniques," IEEE Trans. Energy Convers., vol. 22, no. 2, pp. 439-449, Jun. 2007.

10. S. Jain and V. Agarwal, "Comparison of the performance of maximum power point tracking schemes applied to single-stage grid-connected photovoltaic systems," IET Electr. Power Appl., vol. 1, no. 5, pp. 753-762, Sep. 2007.

11. R. Mastromauro, M. Liserre, and A. Dell'Aquila, "Control issues in single-stage photovoltaic systems: MPPT, current and voltage control," IEEE Trans. Ind Informat., vol. 8, no. 2, pp. 241-254, May 2012. 
12. R. Varma, B. Das, I. Axente, and T. Vanderheide, "Optimal 24-hr utilization of a PV solar system as STATCOM(PV-STATCOM) in a distribution network," in Proc. IEEE Power Energy Soc. Gener. Meet., Jul. 2011, pp. 1-8.

13. A. Yazdani et al., "Modeling guidelines and a benchmark for power system simulation studies of three-phase single-stage photovoltaic systems," IEEE Trans. Power Del., vol. 26, no. 2, pp. 1247-1264, Apr. 2011.

14. F. Delfino, G. Denegri, M. Invernizzi, and R. Procopio, "A control algorithm for the maximum power point tracking and the reactive power injection from grid-connected PV systems," in Proc. IEEE Power Energy Soc. Gener. Meet., Jul. 2010, pp. 1-7.

15. L. Wang and Y.-H. Lin, "Dynamic stability analyses of a photovoltaic array connected to a large utility grid," in Proc. IEEE Power Eng. Soc. Winter Meet., Jan. 2000, vol. 1, pp. 476-480.

16. B. Tamimi, C. Canizares, and K. Bhattacharya, "Modeling and performance analysis of large solar photo-voltaic generation on voltage stability and inter-area oscillations," in Proc. IEEE Power Energy Soc. Gener. Meet., Jul. 2011, pp. 1-6.

17. W. Du, H. Wang, and R. Dunn, "Power system small-signal oscillation stability as affected by large-scale PV penetration," in Proc. IEEE Int. Conf. SUPERGEN, Apr. 2009, pp. 1-6.

18. S. Balathandayuthapani, C. Edrington, S. Henry, and J. Cao, "Analysis and control of a photovoltaic system: Application to a high penetration case study," IEEE Syst. J., vol. 6, no. 2, pp. 213-219, Jun. 2012.

19. A. Yazdani and P. Dash, "A control methodology and characterization of dynamics for a photovoltaic (PV) system interfaced with a distribution network," IEEE Trans. Power Del., vol. 24, no. 3, pp. 1538-1551, Jul. 2009.

20. Bo, Z.Q., Weller, G., Redfern, M.A.: 'Accurate fault location technique for distribution system using fault generated high-frequency transient voltage signals', IEE Proceedings of Generation, Transmission and Distribution, 1999, 146, (1), pp. 73-79

21. Chunju, F., Li, K.K., Chan, W.L., et al.: 'Application of wavelet fuzzy neural network in locating single line to ground fault (SLG) in distribution lines', Electrical Power and Energy Systems, 2007, 29, (6), pp. 497-503

22. Xinzhou, D., Zhongxing, G., Yaozhong, G., et al.: 'Application of wavelet transform in power system fault signal analysis', Proceedings of the CSEE, 1997, 17, (6), pp. 421-424

23. Qingquan, J., Lianguang, L., Yihan, Y.: 'Abrupt change detection with wavelet for small current fault relaying', Proceedings of the CSEE, 2001, 21, (10), pp. 78-82

24. Hanninen, S., Lehtonen, M., Hakola, T., et al.: 'Characteristics of earth faults in power systems with a compensated or an unearthed neutral', IEE 14th International Conference and Exhibition on Electricity Distribution, Jun. 1997, pp. 16/1-16/5

25. Sanjit, K. M.: 'Digital Signal Processing : A Computer-Based Approach ' (The McGraw-Hill Companies, New York, 2000, 4th edn. 2011)

26. Brian S. E., Sabine L., Morven L., et al.: 'Cluster Analysis' (John Wiley Sons, Ltd, Hoboken, 1993,5th edn. 2011 